\title{
Occurrence and removal of organic micropollutants in the treatment of landfill leachate by combined anaerobic-membrane bioreactor technology
}

\author{
XU Yiping, ZHOU Yiqi, WANG Donghong, CHEN Shaohua, \\ LIU Junxin, WANG Zijian*
}

State Key Laboratory of Environmental Aquatic Chemistry, Research Center for Eco-Environmental Sciences, Chinese Academy of Sciences, Beijing 100085, China. E-mail: ypxu@rcees.ac.cn

Received 3 January 2008, revised 18 February 2008; accepted 6 March 2008

\begin{abstract}
Organic micropollutants, with high toxicity and environmental concern, are present in the landfill leachate at much lower levels than total organic constituents (chemical oxygen demand (COD), biochemical oxygen demand (BOD), or total organic carbon (TOC)), and few has been known for their behaviors in different treatment processes. In this study, occurrence and removal of 17 organochlorine pesticides (OCPs), 16 polycyclic aromatic hydrocarbons (PAHs), and technical 4-nonylphenol (4-NP) in landfill leachate in a combined anaerobic-membrane bioreactor (MBR) were investigated. Chemical analyses were performed in leachates sampled from different treatment processes, using solid-phase extraction and gas chromatography with electron capture detector and mass spectrometry. Concentrations of OCPs, PAHs, and 4-NP in the raw leachate were detected within the range from ND (not detected) to 595.2 ng/L, which were as low as only $10^{-7}-10^{-5}$ percentage of TOC (at the concentration of 2,962 $\mathrm{mg} / \mathrm{L}$ ). The removal of 4-NP was mainly established in the MBR process, in agreement with removals of COD, BOD, and TOC. However, the removals of OCPs and PAHs were different, mainly achieved in the anaerobic process. High removal efficiencies of both total organic constituents and organic micropollutants could be achieved by the combined anaerobic-MBR technology. The removal efficiencies of total organic constituents were in the order of BOD $(99 \%)>\operatorname{COD}(89 \%)>$ TOC $(87 \%)$, whereas the removal efficiencies of investigated organic micropollutants were as follows: OCPs $(94 \%)>4-\mathrm{NP}(77 \%)>$ PAHs $(59 \%)$.
\end{abstract}

Key words: anaerobic; landfill leachate; membrane bioreactor; organic micropollutant

\section{Introduction}

Landfill leachate constitutes a very complex mixture, which may contain a large number of xenobiotic organic compounds encountered in the solid waste disposal site or formed as a result of chemical and biological processes within the landfill (Banar et al., 2006; Urase and Miyashita, 2003). Among them, some organic micropollutants identified are highly toxic, carcinogenic, or even mutagenic, such as polycyclic aromatic hydrocarbons (PAHs), halogenated pesticides, phenols, and so on, although they are often found in trace levels $(\mu \mathrm{g} / \mathrm{L}, \mathrm{ng} / \mathrm{L}$ or even lower) (Banar et al., 2006; Ozkaya, 2005). These organic micropollutants may create a potential risk to the quality of receiving water bodies and become a new pollution source of groundwater or surface waters (Alkalay et al., 1998; Baun et al., 2004). Hence, several studies have reported growing concern on identification, occurrence, and toxicity of these organic micropollutants in landfill leachates (Banar et al., 2006; Baun et al., 2003, 2004; Bras

\footnotetext{
* Corresponding author. E-mail: wangzj@rcees.ac.cn.
}

et al., 2000; Castillo and Barcelo, 2001; Grøn et al., 2000; Herbert et al., 2006; Nascimento Filho et al., 2003; Noma et al., 2001; Ozkaya, 2005; Urase and Miyashita, 2003), which are summarized in Table 1. Organic micropollutants contribute little to the level of total organic constituents, such as chemical oxygen demand (COD) and total organic carbon (TOC). Therefore, the main removal of COD and TOC may not indicate the significant decrease of trace organic contaminants, which has been seldom reported.

The treatment of leachate is very complicated, expensive, and generally requires various and combined process applications (Ozturk et al., 2003). Biological techniques, anaerobic and aerobic treatment systems, have been studied in landfill leachate during the last few decades, which have shown high performance. However, there are still some problems and challenges depending on characteristics of leachate (such as age) for application of biological techniques, which are hardly efficient for removal of biorefractory organics (Wiszniowski et al., 2006). Hence, physicochemical processes, such as membrane processes, advanced oxidation processes, and so on, have been widely used as posttreatment of biologically pretreated landfill 
Table 1 Identified organic micropollutants in landfill leachates

\begin{tabular}{|c|c|c|c|c|}
\hline Chemical & Sample & Occurrence level $(\mu \mathrm{g} / \mathrm{L})$ & Analysis method & Reference \\
\hline Alkanes, alkenes & Raw & - & SPME, GC/MS & Banar et al., 2006 \\
\hline \multirow{2}{*}{ Alkylphenols } & Raw & ND-22.1 & SPE, GC/MS & Baun et al., 2003 \\
\hline & Raw & ND-27.3 & SPE, GC/MS & Baun et al., 2004 \\
\hline \multirow[t]{2}{*}{ Bicyclo compounds } & Raw & ND-151 & SPE, GC/MS & Baun et al., 2003 \\
\hline & Raw & ND-255 & SPE, GC/MS & Baun et al., 2004 \\
\hline \multirow[t]{2}{*}{ Bisphenol A } & Raw & ND-8,400 & SPE, GC/MS & Urase and Miyashita, 2003 \\
\hline & After & - & & \\
\hline \multirow[t]{2}{*}{ BTEX } & Raw & ND-278 & LLE, GC/MS & Baun et al., 2003 \\
\hline & Raw & ND-2,220 & LLE, GC/MS & Baun et al., 2004 \\
\hline \multirow[t]{2}{*}{ C3-benzenes } & Raw & ND-50.2 & LLE, GC/MS & Baun et al., 2003 \\
\hline & Raw & ND-152 & LLE, GC/MS & Baun et al., 2004 \\
\hline Chlorinated aliphatics & Raw & ND-8.61 & LLE, GC/MS & Baun et al., 2004 \\
\hline \multirow{4}{*}{ Chlorophenols } & Raw & ND-0.35 & SPE, GC/MS & Baun et al., 2003 \\
\hline & Raw & ND-10.2 & SPE, GC/MS & Baun et al., 2004 \\
\hline & Raw & 5 & XAD-8, GC/MS & Grøn et al., 2000 \\
\hline & Raw & ND-130 & SPME, GC/FID & Ozkaya, 2005 \\
\hline Lactones & Raw & - & SPME, GC/MS & Banar et al., 2006 \\
\hline $\begin{array}{l}\text { Nonylphenol, nonylphenol } \\
\text { ethoxycarboxylates }\end{array}$ & Raw & ND-7.0 & SPE, GC/MS & Baun et al., 2004 \\
\hline \multirow[t]{3}{*}{ Organic acids } & Raw & - & SPME, GC/MS & Banar et al., 2006 \\
\hline & Raw & ND-2.10 & SPE, GC/MS & Baun et al., 2003 \\
\hline & Raw & $0.6-19.3$ & SPE, GC/MS & Baun et al., 2004 \\
\hline Organochlorine pesticides & Raw & ND & SPME, GC/ECD & Bras et al., 2000 \\
\hline Organophosphorus & Raw & 0.66 & SPE, LC-APCI-MS & Castillo and Barcelo, 2001 \\
\hline \multirow[t]{2}{*}{ Pesticides } & Raw & $17.5-260$ & SPE, GC/MS & Baun et al., 2003 \\
\hline & Raw & ND-150 & SPE, GC/MS & Baun et al., 2004 \\
\hline \multirow[t]{4}{*}{ Phthalic acid esters } & Raw & - & SPME, GC/MS & Banar et al., 2006 \\
\hline & Raw & $1-340$ & LLE, GC/MS & Baun et al., 2004 \\
\hline & Raw & $0.78-3.0$ & SPE, LC-APCI-MS & Castillo and Barcelo, 2001 \\
\hline & Raw & - & SPE, GC/MS & Nascimento Filho et al., 2003 \\
\hline Polychlorinated biphenyls & Raw & ND-1.213 & SPME, GC/MS & Herbert et al., 2006 \\
\hline \multirow[t]{4}{*}{ Polycyclic aromatic hydrocarbons } & Raw & - & SPME, GC/MS & Banar et al., 2006 \\
\hline & Raw & ND-305 & SPE, GC/MS & Baun et al., 2003 \\
\hline & Raw & ND-114.7 & SPE, GC/MS & Baun et al., 2004 \\
\hline & Raw & ND-60.529 & SPME, GC/MS & Herbert et al., 2006 \\
\hline
\end{tabular}

Occurrence level: range, or mean value for occurrence level of individual chemical; Raw: raw leachate; After: sample that is after treatment; -: quantitative results not available; ND: not detected.

leachates (Ahn et al., 2002; Chen and Liu, 2006; Ozturk et al., 2003).

In this study, a combined system comprised of a membrane bioreactor (MBR) and an anaerobic filter pretreatment was applied to treat a municipal landfill leachate. The aim of this study was to investigate the occurrence and removal of some representative organic micropollutants in the leachate, PAHs, organochlorine pesticides (OCPs), and 4-nonylphenol (4-NP), by this combined treatment system. The study was also focused on comparison between the removal of these organic micropollutants and total organic constituents (COD, BOD, and TOC).

\section{Materials and methods}

\subsection{Materials}

The calibration mixture of 17 OCPs, including $\alpha$ $\mathrm{HCH}, \beta-\mathrm{HCH}, \gamma-\mathrm{HCH}, \delta-\mathrm{HCH}, p, p^{\prime}$-DDT, $p, p^{\prime}$-DDD, $p, p^{\prime}$-DDE, methoxychlor, heptachlor, heptachlor epoxide, aldrin, dieldrin, endrin, endrin aldehyde, endosulfan I, endosulfan II, and endosulfan sulfate, was purchased from Supelco, USA. Each component at the concentration of $250 \mu \mathrm{g} / \mathrm{ml}$ except methoxychlor at 1,000 $\mu \mathrm{g} / \mathrm{ml}$ in hexane:toluene $(50: 50, V / V)$. The calibration mixture of 16 PAHs, including acenaphthene $(1,000$ $\mu \mathrm{g} / \mathrm{ml})$, acenaphthylene $(2,000 \mu \mathrm{g} / \mathrm{ml})$, anthracene (100 $\mu \mathrm{g} / \mathrm{ml})$, benzo[a]anthracene $(100 \mu \mathrm{g} / \mathrm{ml})$, benzo[a]pyrene (100 $\mu \mathrm{g} / \mathrm{ml})$, benzo[b]fluoranthene $(200 \mu \mathrm{g} / \mathrm{ml})$, benzo[ghi]perylene $(200 \mu \mathrm{g} / \mathrm{ml})$, benzo[k]fluoranthene $(200$ $\mu \mathrm{g} / \mathrm{ml})$, chrysene $(100 \mu \mathrm{g} / \mathrm{ml})$, dibenzo[a,h]anthracene (200 $\mu \mathrm{g} / \mathrm{ml})$, fluoranthene $(200 \mu \mathrm{g} / \mathrm{ml})$, fluorene (200 $\mu \mathrm{g} / \mathrm{ml})$, indeno[1,2,3-cd]pyrene $(100 \mu \mathrm{g} / \mathrm{ml})$, naphthalene $(1,000 \mu \mathrm{g} / \mathrm{ml})$, phenanthrene $(100 \mu \mathrm{g} / \mathrm{ml})$, and pyrene $(100 \mu \mathrm{g} / \mathrm{ml})$, was purchased from Supelco, USA, with each component in methanol:methylene chloride (50:50, $V / V)$. Technical 4-NP (mixture with branched alkyl chain, 99\% purity) was obtained from Acros Organics, USA. Surrogates including tetrachloro- $m$-xylene and decachlorobiphenyl mixture (for OCPs, $200 \mu \mathrm{g} / \mathrm{ml}$ each component in acetone), phenanthrene- $\mathrm{d}_{10}$ (for PAHs, 2,000 $\mu \mathrm{g} / \mathrm{ml}$ in methanol), and bisphenol A- $\mathrm{d}_{16}$ (for 4-NP, 50 $\mathrm{mg}$ ) were all obtained from Supelco, USA. Internal standards including pentachloronitrobenzene (for OCPs, 200 $\mu \mathrm{g} / \mathrm{ml}$ in methylene chloride) and 4- $n$-nonylphenol (for 4NP, $99.7 \%$ purity) were purchased from Supelco, USA, whereas internal standard hexamethylbenzene (for PAHs, 99.5\% purity) was purchased from EQ Laboratories Inc., Germany. The derivatization reagent for 4-NP analysis, $\mathrm{N}$, O-bis (trimethylsilyl) trifluoroacetamide (BSTFA) with $1 \%$ trimethylchlorsilane (TMCS), was obtained from 
Fluka and Riedel-Haën (Switzerland).

All solvents were of HPLC grade, purchased from J.T. Baker, USA. Silica gel (60/200 mesh, ultra pure) and neutral aluminum oxide (50/200 mesh, ultra pure) were obtained from Acros Organics, USA, heated at 180 and $250^{\circ} \mathrm{C}$ for $12 \mathrm{~h}$, respectively, and then both were cooled in a desiccator and deactivated using $3 \%$ of deionized water.

\subsection{Leachate collection}

Landfill leachate samples were collected from A'suwei Municipal Landfill in the north of Beijing, China, which is in operation since 1996. The collected leachate was stored at room temperature before pumped into the treatment system. The whole treatment system consisted of two main parts, an anaerobic filter followed by a membrane bioreactor (MBR). The anaerobic filter was applied as pretreatment, with $60 \mathrm{~L}$ of efficient volume. The MBR was composed of a bioreactor with $80 \mathrm{~L}$ of efficient volume and two membrane modules. Detailed conditions for MBR have been reported by Chen and Liu (2006), the important specifications are given in Table 2.

Table 2 Specifications of the MBR

\begin{tabular}{ll}
\hline Parameter & Description \\
\hline Membrane & $0.22 \mu$ m hollow fiber of \\
& polyvinylidene fluoride (PVDF) \\
Effective membrane area & $0.1 \mathrm{~m}^{2}$ for each membrane module \\
Transmembrane pressure $(\mathrm{kPa})$ & 9.0 \\
Steady-state MLSS $(\mathrm{g} / \mathrm{L})$ & 10.1 \\
Total HRT $(\mathrm{d})$ & 9.5 \\
DO $(\mathrm{mg} / \mathrm{L})$ & 0.85 \\
\hline
\end{tabular}

MLSS: activated sludge concentration; HRT: hydrodynamic retention time; DO: dissolved oxygen.

The activated sludge taken from a sewage treatment plant in Beijing was fed in the MBR, and the start-up procedure of MBR has been described in detail in the other article (Chen and Liu, 2006). Water samples were collected from 4 stages after continuous operation for 114 $\mathrm{d}$ in the treatment system, including raw leachate from landfill (L1), the effluent from anaerobic filter (L2), the supernatant of mixed liquor in MBR (L3), as well as the effluent from MBR (final effluent, L4). Water samples were collected in brown glass bottles with glass seals and were kept at $4^{\circ} \mathrm{C}$ until extraction. Storage period did not exceed $7 \mathrm{~d}$.

\subsection{Sample preparation}

Water samples were spiked with surrogates for different analytes before extraction. For OCP and PAH analysis, 1 $\mathrm{L}$ of each water sample was extracted with a 6-ml (500 $\mathrm{mg}$ ) Supelclean LC-18 SPE cartridge (Supelco, USA). The cartridge was prewashed with $5 \mathrm{ml}$ of methylene chloride and conditioned with $5 \mathrm{ml}$ of methanol followed by $5 \mathrm{ml}$ of deionized water. After the extraction, the cartridge was then eluted using $10 \mathrm{ml}$ of methylene chloride. For 4-NP analysis, $1 \mathrm{~L}$ of each water sample was first adjusted to pH 2 using $6 \mathrm{~mol} / \mathrm{L}$ of $\mathrm{HCl}$ and then extracted using a 6ml (500 mg) Oasis ${ }^{\circledR}$ HLB SPE cartridge (Waters Corp., USA). The cartridge was prewashed with $5 \mathrm{ml}$ of methyl tert-butyl ether (MTBE) and conditioned with $5 \mathrm{ml}$ of methanol followed by $5 \mathrm{ml}$ of deionized water. After the extraction, the cartridge was then eluted with $10 \mathrm{ml}$ of methanol/MTBE mixture (10:90, $V / V)$. All extracts were evaporated to near dryness under a gentle flow of nitrogen and dissolved in $1 \mathrm{ml}$ of hexane before cleanup.

The OCP and PAH extracts were cleaned up using a silica gel/alumina composite chromatographic column, which was composed of $5 \mathrm{~g}$ of silica gel and $5 \mathrm{~g}$ of aluminum oxide. Seventy milliliter of methylene chloride/hexane mixture $(30: 70, V / V)$ elution was collected. The 4-NP extract was cleaned up using a silica gel chromatographic column, which was composed of $4 \mathrm{~g}$ of silica gel. Thirty milliliter of ethyl acetate/hexane mixture $(25: 75, \mathrm{~V} / \mathrm{V})$ elution was collected.

All the elution was evaporated to dryness in a rotary evaporator (Büchi Laboratory Equi., Switzerland). The residue of OCP and PAH sample was then dissolved in 1 $\mathrm{ml}$ of hexane and added with the internal standards. The residue of 4-NP sample was first dissolved in $200 \mu \mathrm{l}$ of hexane, then silylated with $50 \mu \mathrm{l}$ of derivatization reagent (BSTFA with $1 \%$ TMCS), reacted for $2 \mathrm{~h}$ at $60^{\circ} \mathrm{C}$, and finally dissolved in $1 \mathrm{ml}$ of hexane, which were added with the internal standard.

\subsection{Chromatographic analysis}

The analysis of OCPs was carried out using an Agilent 6890 series gas chromatograph equipped with a $\mathrm{Ni}^{63} \mathrm{mi}-$ cro electron capture detector (GC/ $\mu$-ECD). Analytes were separated on two different capillary gas chromatograph columns. A DB-5 $(30 \mathrm{~m} \times 0.25 \mathrm{~mm} \times 0.25 \mu \mathrm{m})$ column served as the primary column for pesticide quantification, whereas an SPB-1701 $(30 \mathrm{~m} \times 0.25 \mathrm{~mm} \times 0.25 \mu \mathrm{m})$ column was used to confirm the identified pesticides by relative retention times. Detailed instrument conditions are shown in Table 3.

PAHs and 4-NP were all analyzed on an Agilent 6890 GC connected to a 5973 mass spectrometry (GC/MS), equipped with a DB-5MS $(60 \mathrm{~m} \times 0.25 \mathrm{~mm} \times 0.25 \mu \mathrm{m})$ capillary gas chromatograph column. Detailed instrument conditions are shown in Table 3 . The mass spectrometry was operated in the selected ion monitoring mode for quantification, and at least two ions for each target analyte were monitored.

All the analytes were quantified by peak area using the internal standard method. Qualitative analysis and detection limit of each analyte are shown in Table 4. Mean recoveries of OCPs, PAHs, and 4-NP through entire analytical procedures were in the range of $61 \%-142 \%$, $58 \%-121 \%$, and $81 \%$, respectively, which were determined with laboratory fortified blanks.

\section{Results and discussion}

\subsection{Characteristics of leachate}

Characteristics of the leachate are shown in Table 5. The concentrations of COD were measured as soluble COD (SCOD) in this study. The raw landfill leachate (L1) had a high $\mathrm{BOD} / \mathrm{COD}$ ratio of 0.71 , which suggested that 
Table 3 Instrument conditions of chromatographic analysis

\begin{tabular}{|c|c|c|c|c|c|}
\hline Analyte & Column & Oven & Inlet & Detector & Carrier gas \\
\hline \multirow[t]{2}{*}{ OCPs } & DB-5 & $\begin{array}{l}\text { Initially } 85^{\circ} \mathrm{C} \text { for } 2 \mathrm{~min} \text {, and increased by } 15^{\circ} \mathrm{C} / \mathrm{min} \\
\text { to } 160^{\circ} \mathrm{C} \text {, then increased by } 5^{\circ} \mathrm{C} / \mathrm{min} \text { to the } \\
\text { final temperature } 280^{\circ} \mathrm{C} \text { (hold for } 20 \mathrm{~min} \text { ) }\end{array}$ & $250^{\circ} \mathrm{C}$, splitless & $\mathrm{ECD}, 300^{\circ} \mathrm{C}$ & Nitrogen, $2.0 \mathrm{ml} / \mathrm{min}$ \\
\hline & SPB-1701 & $\begin{array}{l}\text { Initially } 60^{\circ} \mathrm{C} \text { for } 2 \mathrm{~min} \text {, and increased by } 20^{\circ} \mathrm{C} / \mathrm{min} \\
\text { to } 160^{\circ} \mathrm{C} \text {, then increased by } 4^{\circ} \mathrm{C} / \mathrm{min} \text { to the final } \\
\text { temperature } 260^{\circ} \mathrm{C} \text { (hold for } 20 \mathrm{~min} \text { ) }\end{array}$ & $200^{\circ} \mathrm{C}$, splitless & $\mathrm{ECD}, 280^{\circ} \mathrm{C}$ & Nitrogen, $0.9 \mathrm{ml} / \mathrm{min}$ \\
\hline PAHs & DB-5MS & $\begin{array}{l}\text { Initially } 50^{\circ} \mathrm{C} \text { for } 2 \mathrm{~min} \text {, and increased by } \\
20^{\circ} \mathrm{C} / \mathrm{min} \text { to } 200^{\circ} \mathrm{C} \text { (hold for } 2 \mathrm{~min} \text { ), increased by } \\
5^{\circ} \mathrm{C} / \mathrm{min} \text { to } 240^{\circ} \mathrm{C} \text { (hold for } 2 \mathrm{~min} \text { ), } \\
\text { then increased by } 3^{\circ} \mathrm{C} / \mathrm{min} \text { to the final temperature }\end{array}$ & $\begin{array}{l}290^{\circ} \mathrm{C} \\
\text { (hold for } 15 \mathrm{~min} \text { ) } \\
280^{\circ} \mathrm{C}, \text { splitless }\end{array}$ & $\mathrm{MS}, 280^{\circ} \mathrm{C}$ & Helium, $1.0 \mathrm{ml} / \mathrm{min}$ \\
\hline 4-NP & DB-5MS & $\begin{array}{l}\text { Initially } 100^{\circ} \mathrm{C} \text { for } 1 \mathrm{~min} \text {, and increased by } 25^{\circ} \mathrm{C} / \mathrm{min} \\
\text { to } 180^{\circ} \mathrm{C} \text { (hold for } 15 \mathrm{~min} \text { ), then increased by } 20^{\circ} \mathrm{C} / \mathrm{min} \\
\text { to the final temperature } 300^{\circ} \mathrm{C} \text { (hold for } 15 \mathrm{~min} \text { ) }\end{array}$ & $280^{\circ} \mathrm{C}$, splitless & $\mathrm{MS}, 280^{\circ} \mathrm{C}$ & Helium, $1.0 \mathrm{ml} / \mathrm{min}$ \\
\hline
\end{tabular}

OCP: organochlorine pesticides; PAH: polycyclic aromatic hydrocarbons; 4-NP: 4-nonylphenol.

Table 4 Qualitative analysis and detection limit of each investigated organic micropollutant

\begin{tabular}{|c|c|c|c|c|c|c|}
\hline $\mathrm{OCP}$ & $\begin{array}{l}\text { RT on DB-5 } \\
(\min )\end{array}$ & $\begin{array}{l}\text { RT on SPB-1701 } \\
(\mathrm{min})\end{array}$ & $\begin{array}{l}\text { Detection } \\
\text { limit }(\mathrm{ng} / \mathrm{L})\end{array}$ & $\mathrm{PAH}$ and 4-NP & Qualifier ion & $\begin{array}{l}\text { Detection } \\
\text { limit }(\mathrm{ng} / \mathrm{L})\end{array}$ \\
\hline$\alpha-\mathrm{HCH}$ & 9.684 & 15.489 & 0.41 & Naphthalene & 128,102 & 5.0 \\
\hline$\beta-\mathrm{HCH}$ & 10.335 & 19.402 & 0.46 & Acenaphthylene & 152,76 & 13.0 \\
\hline$\gamma-\mathrm{HCH}$ & 10.477 & 16.845 & 0.57 & Acenaphthene & 154,76 & 5.2 \\
\hline$\delta-\mathrm{HCH}$ & 11.107 & 20.321 & 0.71 & Fluorene & 166,139 & 2.9 \\
\hline$p, p^{\prime}$-DDT & 19.163 & 27.268 & 0.99 & Phenanthrene & 178,76 & 0.5 \\
\hline$p, p^{\prime}$-DDD & 17.951 & 26.472 & 1.85 & Anthracene & 178,89 & 1.5 \\
\hline$p, p^{\prime}$-DDE & 16.606 & 23.434 & 1.57 & Fluoranthene & 202,101 & 1.0 \\
\hline Methoxy-chlor & 20.346 & 29.945 & 5.47 & Pyrene & 202,101 & 0.9 \\
\hline Aldrin & 13.336 & 18.833 & 0.81 & Benzo[a]anthracene & 228,114 & 1.4 \\
\hline Dieldrin & 16.488 & 23.907 & 0.60 & Chrysene & 228,114 & 1.4 \\
\hline Endrin & 17.152 & 24.728 & 0.82 & Benzo[b]fluoranthene & 252,113 & 2.6 \\
\hline Endrin aldehyde & 18.116 & 28.126 & 0.74 & Benzo[k]fluoranthene & 252,113 & 4.1 \\
\hline Endosulfan I & 15.655 & 22.471 & 0.89 & Benzo[a]pyrene & 252,113 & 1.3 \\
\hline Endosulfan II & 17.475 & 26.557 & 0.70 & Indeno[1,2,3-cd]pyrene & 276,138 & 1.2 \\
\hline Endosulfan sulfate & 18.415 & 29.420 & 0.47 & Dibenzo[a,h]anthracene & 278,139 & 2.3 \\
\hline Heptachlor & 12.366 & 17.807 & 1.38 & Benzo[ghi]perylene & 276,138 & 4.1 \\
\hline Heptachlor epoxide & 14.565 & 21.382 & 1.15 & 4-NP & 292,179 & 10 \\
\hline
\end{tabular}

RT: retention time.

Table 5 Characteristics of the landfill leachate during the treatment process

\begin{tabular}{lllll}
\hline Parameter & L1 & L2 & L3 & L4 \\
\hline pH & 8.0 & 8.3 & 8.4 & 8.4 \\
SCOD (mg/L) & 10,084 & 9,357 & 1,955 & 1,007 \\
BOD $(\mathrm{mg} / \mathrm{L})$ & 7,200 & 5,600 & 40 & 24 \\
TOC $(\mathrm{mg} / \mathrm{L})$ & 2,962 & 2,917 & 753 & 410 \\
TN $(\mathrm{mg} / \mathrm{L})$ & 2,445 & 2,468 & 874 & 848 \\
\hline
\end{tabular}

SCOD: soluble COD; L1: raw landfill leachate; L2: leachate after anaerobic filtration; L3: supernatant of mixed liquor in MBR; L4: final effluent.

the leachate was collected from a young and biodegradable landfill. High removal efficiencies were achieved for SCOD, BOD, and TOC by the combined anaerobic-MBR treatment system due to the relatively high biodegradability of leachate, as indicated in Table 5.

\subsection{Occurrence of organic micropollutants}

The landfill leachate during all the treatment processes was screened for 34 organic micropollutants, including 17 OCPs, 16 PAHs, and technical 4-NP. Detected pollutants were present in much lower concentrations (at the level of $\mathrm{ng} / \mathrm{L}$ ) in the landfill leachate, compared with total organic constituents (at the level of thousands of $\mathrm{mg} / \mathrm{L}$ ), as shown in Table 6.

The total concentration of OCPs ( $\Sigma \mathrm{OCPs})$ in the raw landfill leachate (L1) was only $203.5 \mathrm{ng} / \mathrm{L}$, in which $\gamma$ $\mathrm{HCH}, p, p^{\prime}$-DDT, and $p, p^{\prime}$-DDE were detected. During the treatment processes, $p, p^{\prime}$-DDD, another metabolite of $p, p^{\prime}$-DDT, was also checked out. Organochlorine pesticides residue has been seldom reported in landfill leachates.

Polycyclic aromatic hydrocarbons were present in concentrations higher than those of OCPs in the leachate. Twelve PAHs were detected during the treatment processes, and main components were low molecular-weight PAHs, which are listed in Table 6. The total concentrations of PAHs ( $\sum$ PAHs) were in the range of 485.2-1,188.2 $\mathrm{ng} / \mathrm{L}$. The main component of PAHs in the raw leachate (L1) was acenaphthylene, at a concentration of $595.2 \mathrm{ng} / \mathrm{L}$. Contamination of PAH in this leachate was not very high, as the total amounts of PAHs have been reported in landfill leachates at the concentrations up to $114,273 \mathrm{ng} / \mathrm{L}$ (Herbert et al., 2006).

4-Nonylphenol was detected during all the treatment processes at concentrations of 92-482 ng/L. Similarly, 4NP has been identified in landfill leachates at levels of below detection limit to 7,000 $\mathrm{ng} / \mathrm{L}$ in the literature (Baun et al., 2004). 
Table 6 Concentrations of organic micropollutants detected in the leachate during treatment process

\begin{tabular}{|c|c|c|c|c|c|c|}
\hline \multirow[t]{2}{*}{ Analyte } & \multicolumn{4}{|c|}{ Concentrations (ng/L) } & \multirow[t]{2}{*}{ Mean RPD (\%) } & \multirow[t]{2}{*}{ Blank } \\
\hline & L1 & L2 & L3 & L4 & & \\
\hline$\gamma-\mathrm{HCH}$ & 138.7 & ND & 20.5 & 8.7 & 4 & ND \\
\hline$p, p^{\prime}$-DDT & 51.6 & ND & ND & ND & 8 & ND \\
\hline$p, p^{\prime}-\mathrm{DDD}$ & ND & 4.2 & ND & ND & 8 & ND \\
\hline$p, p^{\prime}$-DDE & 13.2 & 11.9 & 11.2 & 3.1 & 7 & ND \\
\hline Naphthalene & ND & 71.3 & 34.4 & 72.9 & 4 & 5.1 \\
\hline Acenaphthylene & 595.2 & ND & 20.1 & 54.9 & 6 & 8.7 \\
\hline Acenaphthene & ND & ND & 3.9 & ND & 2 & ND \\
\hline Fluorene & ND & 181.8 & 157.8 & 144.7 & 11 & ND \\
\hline Phenanthrene & ND & 129.6 & 136.7 & 152.3 & 2 & ND \\
\hline Fluoranthene & 122.6 & ND & ND & ND & 8 & ND \\
\hline Pyrene & 194.8 & ND & ND & ND & 5 & ND \\
\hline Benzo[a]anthracene & 129.0 & 106.1 & 137.8 & 39.8 & 8 & ND \\
\hline Chrysene & 48.3 & ND & 13.9 & 15.6 & 15 & ND \\
\hline Benzo[b]fluoranthene & 21.3 & 10.7 & 13.1 & 5.0 & 11 & ND \\
\hline Benzo[a]pyrene & 30.4 & ND & ND & ND & 18 & ND \\
\hline Benzo[ghi]perylene & 46.6 & ND & ND & ND & 13 & ND \\
\hline 4-NP & 400 & 482 & 99 & 92 & 5 & ND \\
\hline
\end{tabular}

ND: not detected; RPD: relative percentage deviations for sample duplicates. L1, L2, L3, and L4 are the same as that in Table 5.

\subsection{Removal of trace organic contaminants in leachate treatment process}

Figure 1 shows the behaviors of investigated organic micropollutants (OCPs, PAHs, and 4-NP at levels of ng/L) and total organic constituents (SCOD, BOD, and TOC at levels of $\mathrm{mg} / \mathrm{L}$ ), after each treatment process in the combined leachate treatment systems.

The breakdown of OCPs was mainly achieved in the anaerobic process. A $94 \%$ removal of $\gamma-\mathrm{HCH}$ could be obtained in final, resulting in the decrease of concentration from 138.7 to $8.7 \mathrm{ng} / \mathrm{L}$ (Table 6). Previous work has demonstrated that $\beta-\mathrm{HCH}$ and $\delta-\mathrm{HCH}$ are more persistent than $\alpha-\mathrm{HCH}$ and $\gamma-\mathrm{HCH}$ (Langenhoff et al., 2002; Phillips et al., 2005; Rath et al., 1998). However, none of other $\mathrm{HCH}$ isomers except $\gamma-\mathrm{HCH}$ were detected in the leachate, which indicated that there were no marked transformation processes between $\mathrm{HCH}$ isomers throughout the treatment processes. $\gamma-\mathrm{HCH}$ in the leachate was probably dechlorinated into more stable products, such as chlorobenzenes and chlorophenols (Langenhoff et al., 2002). The removal of $p, p^{\prime}$-DDTs was as high as $99 \%$ by the integrate treatment system. Dechlorinated metabolic

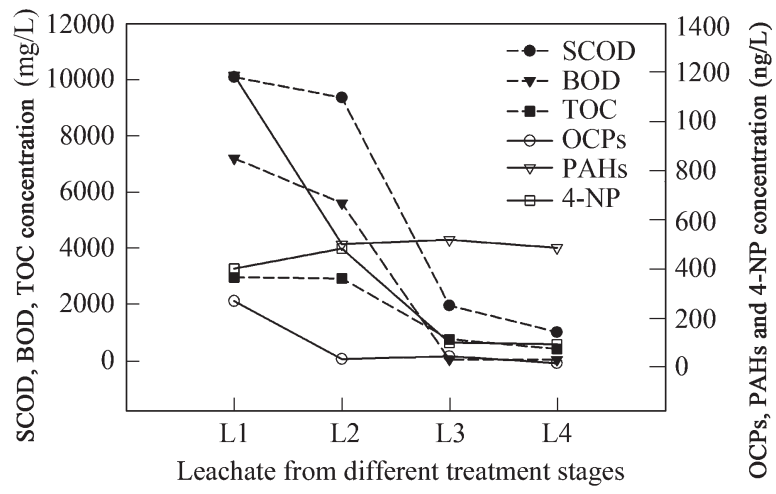

Fig. 1 Behavior of total organic constituents and trace organic contaminants in the treatment processes. L1, L2, L3, and L4 are the same as that in Table 5. transformation of DDT under anaerobic conditions leads to the metabolite DDD, and evidence has presented that the preferential metabolic pathway via DDD can avoid the formation of DDE (Mitra and Raghu, 1998). In this study, $p, p^{\prime}$-DDT preferred to degrade to $p, p^{\prime}$-DDD, whereas the total amount of $p, p^{\prime}$-DDTs was dissipated markedly after anaerobic treatment process. A possible reason could be the decrease of total DDTs because DDD was not the final metabolite and further degradation of DDD could occur under anaerobic conditions, which has been already confirmed (Mitra and Raghu, 1998). The metabolite DDE has been shown to be more persistent than either DDT or DDD (Kveseth et al., 1979). Hence, $p, p^{\prime}$-DDE was hardly removed throughout the treatment processes, and it was the only metabolite that could be found in final effluent (L4) (Table 6).

Most of PAHs in leachate were also removed after anaerobic process. Under anaerobic conditions, stability of PAHs makes it difficult to cleave the ring without oxygen. However, recent research has shown that unsubstituted low molecular polycyclic aromatic compounds can be degraded under nitrate-reducing, iron-reducing, sulfatereducing, and methanogenic conditions (Bedessem et al., 1997; Rockne and Strand, 1998; Sharak Genthner et al., 1997). In this study, most of the decrease in low molecular weight PAHs in the leachate was probably attributed to this type of anaerobic biodegradation, which should be confirmed by further research to find out the electron acceptor conditions in the stimulated biodegradation of PAHs during this biological pretreatment process.

The removal of 4-NP was different with OCPs and PAHs, which was mainly achieved in the MBR treatment system. A significant drop of 4-NP was observed in the MBR systems, from 482 to $92 \mathrm{ng} / \mathrm{L}$ (Table 6). However, a slight increase in concentration of 4-NP was observed after the anaerobic treatment (from 400 to $482 \mathrm{ng} / \mathrm{L}$, a minus removal efficiency of $-21 \%$ as shown in Table 7 ). Nonylphenol has been reported as one of the degradation products of nonylphenol polyethoxylates (NPnEOs) (Hoai et al., 2003), which was found to be hardly degraded under 
Table 7 Removal efficiency of different analytes during different treatment processes

\begin{tabular}{lcccc}
\hline Analyte & \multicolumn{4}{c}{ Removal efficiency (\%) } \\
\cline { 2 - 5 } & Anaerobic & Bioreactor & Membrane & Integrate treatment \\
\hline SCOD & 7 & 73 & 9 & 89 \\
BOD & 22 & 77 & 0 & 99 \\
TOC & 2 & 73 & 12 & 87 \\
$\sum$ OCPs & 88 & -4 & 10 & 94 \\
$\sum$ PAHs & 58 & -2 & 3 & 59 \\
4-NP & -21 & 96 & 2 & 77 \\
\hline
\end{tabular}

Integrate treatment: treatment throughout all the processes.

anaerobic conditions (Angelidaki et al., 2000).

The comparison of removal efficiencies between organic micropollutants and total organic constituents in the leachate after each treatment process by anaerobic-MBR technology is listed in Table 7, where the MBR treatment is divided into two processes, the bioreactor (aerobic) and membrane process (ultrafiltration).

In the landfill leachate used in this study, concentrations of organic micropollutants such as OCPs and PAHs were as low as only $10^{-7}-10^{-5}$ percentage of TOC. Therefore, decrease of SCOD, BOD, and TOC could hardly indicate the reduction of these organic micropollutants. Main removals of them were performed after different processes in this combined treatment system. For total organic constituents, $73 \%$ of SCOD, $77 \%$ of BOD, and $73 \%$ of TOC in the raw leachate could be eliminated mainly in the bioreactor. Similarly, effective removal of 4-NP was also achieved in the bioreactor. However, $88 \%$ of OCPs and $58 \%$ of PAHs were mainly removed through the anaerobic process.

High removals of SCOD, BOD, and TOC were achieved by this combined anaerobic-MBR treatment system, with total removal efficiencies of $89 \%, 99 \%$, and $87 \%$, respectively. However, there still remained 1,007 and $410 \mathrm{mg} / \mathrm{L}$ of SCOD and TOC (Table 5), respectively, in the final effluent. It suggested that there were some biorefractory organics stick to the leachate, which could be hardly removed by both biological process and membrane process. Organochlorine pesticides had higher removal efficiencies than other two kinds of organic micropollutants investigated in this study. Hence, in general, the total removal efficiencies of organic micropollutants were in the order as follows: OCPs > 4-NP > PAHs.

\section{Conclusions}

We reported the removal efficiencies of trace organic contaminants, OCPs, PAHs, and 4-NPs, in the treatment of landfill leachate by combined anaerobic-MBR technology. Organochlorine pesticides, PAHs, and 4-NP were all detected in the raw leachate at levels of ND-595.2 ng/L, which were as low as only $10^{-7}-10^{-5}$ percentage of TOC (at the level of $2,962 \mathrm{mg} / \mathrm{L}$ ).

In general, high removals of both total organic constituents and trace organic contaminants could be achieved by the combined anaerobic-MBR technology. 94\%, 59\%, and $77 \%$ of OCPs, PAHs, and 4-NP, respectively, could be removed efficiently throughout leachate treatment processes. Removals of SCOD, BOD, and TOC, in agreement with 4-NP, were mainly performed in the bioreactor. However, the effective treatment process of OCPs and PAHs was anaerobic pretreatment.

It can be concluded that to evaluate work efficiencies of treatment techniques more properly, behaviors of both total organic constituents and organic micropollutants with great environmental concerns should be considered and investigated carefully.

\section{Acknowledgments}

This work was supported by the National Natural Science Foundation of China (No. 50538090), the National Basic Research Program (973) of China (No. 2007CB407301) and ST Program of Beijing Municipality (No. D0706007040291-01).

\section{References}

Ahn W Y, Kang M S, Yim S K, Choi K H, 2002. Advanced landfill leachate treatment using an integrated membrane process. Desalination, 149(1-3): 109-114.

Alkalay D, Guerrero L, Lema J M, Mendez R, Chamy R, 1998. Review: Anaerobic treatment of municipal sanitary landfill leachates: The problem of refractory and toxic components. World J Microbio Biotechnol, 14(3): 309-320.

Angelidaki I, Mogensen A S, Ahring B K, 2000. Degradation of organic contaminants found in organic waste. Biodegradation, 11(6): 377-383.

Banar M, Özkan A, Kürkçüoğlu M, 2006. Characterization of the leachate in an urban landfill by physicochemical analysis and solid phase microextraction-GC/MS. Environ Monit Assess, 121(1): 437-457.

Baun A, Ledin A, Reitzel L A, Bjerg P L, Christensen T H, 2004. Xenobiotic organic compounds in leachates from ten Danish MSW landfills - chemical analysis and toxicity tests. Water Res, 38(18): 3845-3858.

Baun A, Reitzel L A, Ledin A, Christensen T H, Bjerg P L, 2003. Natural attenuation of xenobiotic organic compounds in a landfill leachate plume (Vejen, Denmark). J Contamt Hydrol, 65(3-4): 269-291.

Bedessem M E, Swoboda-Colberg N G, Colberg P J S, 1997. Naphthalene mineralization coupled to sulfate reduction in aquifer-derived enrichments. FEMS Microbiol Lett, 152(2): 213-218.

Bras I, Santos L, Alves A, 2000. Monitoring organochlorine pesticides from landfill leachates by gas chromatographyelectron-capture detection after solid-phase microextraction. J Chromatogr A, 891(2): 305-311.

Castillo M, Barcelo D, 2001. Characterisation of organic pollutants in textile wastewaters and landfill leachate by using toxicity-based fractionation methods followed by liquid and gas chromatography coupled to mass spectrometric detection. Anal Chim Acta, 426(2): 253-264.

Chen S, Liu J, 2006. Landfill leachate treatment by MBR: Performance and molecular weight distribution of organic contaminant. Chin Sci Bull, 51(23): 2831-2838.

Grøn C, Christensen J B, Jensen D L, Kjeldsen P, Østfeldt P, 2000. Organic halogens in landfill leachates. Water, Air, Soil Pollut, 120(3-4): 331-345.

Herbert P, Silva A, João M, Santos L, Alves A, 2006. Determina- 
tion of semi-volatile priority pollutants in landfill leachates and sediments using microwave-assisted headspace solidphase microextraction. Anal Bioanal Chem, 386(2): 324331.

Hoai P M, Tsunoi S, Ike M, Kuratani Y, Kudou K, Viet $\mathrm{P} \mathrm{H}$ et al., 2003. Simultaneous determination of degradation products of nonylphenol polyethoxylates and their halogenated derivatives by solid-phase extraction and gas chromatography-tandem mass spectrometry after trimethylsilylation. J Chromatogr A, 1020(2): 161-171.

Kveseth N J, Bjerk J E, Fimreite N, Stenersen J, 1979. Residues of DDT in a norwegian fruitgrowing district two and four years after the termination of DDT usage. Arch Environ Contam Toxicol, 8(2): 201-212.

Langenhoff A A M, Staps J J M, Pijls C, Alphenaar A, Zwiep G, Rijnaarts H H M, 2002. Intrinsic and stimulated in situ biodegradation of hexachlorocyclohexane $(\mathrm{HCH})$. Water, Air, Soil Pollut: Focus, 2(3): 171-181.

Mitra J, Raghu K, 1998. Long term DDT pollution in tropical soils: Effect of DDT and degradation products on soil microbial activities leading to soil fertility. Bull Environ Contam Toxicol, 60(4): 585-591.

Nascimento Filho I d, Muhlen C V, Schossler P, Bastos Caramao E, 2003. Identification of some plasticizers compounds in landfill leachate. Chemosphere, 50(5): 657-663.

Noma Y, Yamane S, Kida A, 2001. Adsorbable organic halides (AOX), AOX formation potential, and PCDDs/DFs in landfill leachate and their removal in water treatment processes.
J Mater Cycles Waste Manage, 3(2): 126-134.

Ozkaya B, 2005. Chlorophenols in leachates originating from different landfills and aerobic composting plants. $J$ Hazard Mater, 124(1-3): 107-112.

Ozturk I, Altinbas M, Koyuncu I, Arikan O, Gomec-Yangin C, 2003. Advanced physico-chemical treatment experiences on young municipal landfill leachates. Waste Manage, 23(5): 441-446.

Phillips T M, Seech A G, Lee H, Trevors J T, 2005. Biodegradation of hexachlorocyclohexane $(\mathrm{HCH})$ by microorganisms. Biodegradation, 16(4): 363-392.

Rath A K, Ramakrishnan B, Rath A K, Kumaraswamy S, Bharati $\mathrm{K}$, Singla $\mathrm{P}$ et al., 1998. Effect of pesticides on microbial biomass of flooded soil. Chemosphere, 37(4): 661-671.

Rockne K J, Strand S E, 1998. Biodegradation of bicyclic and polycyclic aromatic hydrocarbons in anaerobic enrichments. Environ Sci Technol, 32(24): 3962-3967.

Sharak Genthner B R, Townsend G T, Lantz S E, Mueller J G, 1997. Persistence of polycyclic aromatic hydrocarbon components of creosote under anaerobic enrichment conditions. Arch Environ Contam Toxicol, 32(1): 99-105.

Urase T, Miyashita K, 2003. Factors affecting the concentration of bisphenol a in leachates from solid waste disposal sites and its fate in treatment processes. J Mater Cycles Waste Manage, 5(1): 77-82.

Wiszniowski J, Robert D, Surmacz-Gorska J, Miksch K, Weber J, 2006. Landfill leachate treatment methods: A review. Environ Chem Lett, 4(1): 51-61. 